\title{
A semi-automatic method to determine the wood failure percentage on shear test specimens
}

\author{
Tina Künniger
}

Published online: 12 April 2008

(c) Springer-Verlag 2008

Subject An alternative method to quantitatively determine the wood failure percentage on shear test specimens was developed, experimentally tested and successfully applied to specimens with typical combinations of adhesive types and wood species used by the glulam industry in Switzerland. The method consists of a staining technique for a better differentiation of wood fibers and adhesive, and an image processing procedure for a standardized estimation of the fractured surface ratio covered by wood fibers and adhesive, respectively. The semi-automatic method allows for a more objective determination of wood failure percentage and is suitable for quality control in the glulam industry.

\section{Introduction}

To provide an adequate bonding quality of their products, glulam manufacturers have to perform shear tests on specimens which are cut out of beams of their running production. Shear strength is measured and wood fiber percentage (graded as $0 \%$ to $100 \%$ wood failure) is estimated to confirm the bonding quality according to EN 386. A major problem to estimate the wood fiber percentage is the difficult perceptibility of adhesive on the fractured surface especially if transparent adhesives like 1P-PUR or MUF are used. Craftsmen report that a deviant estimation of more than $20 \%$ wood failure is not uncommon. Glulam industry requires a standardized method for estimating the wood failure percentage which is inexpensive to install and simple to apply.

T. Künniger (

Wood Laboratory, Empa, Swiss Federal Laboratories for Materials Testing and Research,

Ueberlandstrasse 129 ,

8600 Duebendorf, Switzerland

e-mail: tina.kuenniger@empa.ch

\section{Materials and methods}

Based on a literature review on contrast staining for wood adhesive identification (Dibuz and Shelton 1967, Gibson and Krahmer 1980, Ginzel and Stegmann 1970, Paulitsch 1986, Plath 1970, Schriever 1981, Zeppenfeld and Grunwald 2005) several staining techniques were selected and tested on over 450 shear test specimens which were produced with different wood-adhesive combinations: Norway spruce (Picea abies), European larch (Larix decidua) and ash (Fraxinus excelsior); 1P-PUR, MUF, UF, MF, 2P-EPI and PRF.

For each combination, two $25 \mathrm{~mm}$ thick, planed lamina were spread with adhesive, sandwiched together and pressed under laboratory conditions. All commercial adhesives are classified as type II adhesives according to EN 301 for use in structural applications. The applied amount of adhesive and all processing parameters were in accordance with manufacturer recommendations. The bonded specimens were stored for at least 7 days at standard conditions $\left(20^{\circ} \mathrm{C} / 65 \%\right.$ $\mathrm{RH}$ ) prior to further processing to individual shear test specimens.

The shear strength of glue lines was determined according to EN 392. Additionally, some previously tested specimens were supplied by the Swiss glulam industry for contrast staining and further assessment.

The staining solutions were applied on fracture surfaces of the specimens by brushing or spraying. Stained specimens were stored for approx. 30 minutes at $20^{\circ} \mathrm{C}$ and $50 \% \mathrm{RH}$ to allow for a reaction of the dye with either the wood or the adhesive matrix to generate a sufficient color contrast. The most promising staining technique for every wood-adhesive combination was selected and the stained specimens were analyzed with the image processing software. 
DatInf ${ }^{\circledR}$ Scientific Color (2007) is a commercial image analysis software for sizing areas in digital images which are distinguishable in terms of color. The software runs on standard-PCs and supports different kinds of image formats e.g. BMP, JPG, and TIF.

For comparison of results of the visual rating currently applied by the glulam industry and the method presented in this paper, both methods were applied on each shear test specimen. First, the fractured surfaces were scanned and the images printed. Then, the percentage wood failure was estimated on the fractured surfaces of the shear test specimens by visual assessment by two people. These results were marked on the paper prints. Afterwards, the specimens were treated with a proper solution for contrast staining. The stained fracture surfaces were scanned again and finally semi-automatically assessed by the image processing software.

Statistical analysis was performed to compare the results and describe the differences between these two methods. For every specimen the difference in results (wood failure percentage WFP) between visual estimation (old method) and semi-automatic method (new method) was calculated as:

$\Delta \mathrm{WFP}=\mathrm{WFP}_{\text {old method }}-\mathrm{WFP}_{\text {new method }}[\%]$.

Statistical analysis was performed for various specimen groups of wood-adhesive combinations.

\section{Results and discussion}

For the tested wood-adhesive combinations the acid-base indicator (Dibuz and Shelton 1967) and/or the detection reagent DACA (Paulitsch 1986) induced sufficient color contrast between wood and adhesive to allow for the semi- automatic measurement of the wood failure percentage with the DatInf ${ }^{\circledR}$ Scientific Color software (Fig. 1). In combination with 1P-PUR, MUF, MF and 2P-EPI wood species with $\mathrm{pH}<5.8$ (e.g. spruce and larch wood) showed a satisfactory contrast in color when stained with the acid-base indicator (adhesive green; wood orange to dark red), while wood species with $\mathrm{pH}>5.8$ (e.g. ash) had to be stained with DACA to produce a satisfactory color contrast between wood fiber (light green to blue) and adhesive (pink). For UF resin the acid-base indicator was suitable for wood species with $\mathrm{pH}>5.8$ and DACA for wood species with $\mathrm{pH}<5.8$. The dark brown color of PRF causes a good color contrast in general, which can be further improved by staining the wood with malachite green.

In Fig. 2 an assessment procedure is proposed.

On the basis of general experience, the wide range of shade and pattern on the colored fracture surfaces makes a fully-automatic assessment impossible, thus a plausibility appraisal of the results is still required.

Statistical analysis of all result data showed that the difference between the visual and the semi-automatic method is dependent on the wood species and the adhesive type and to a lesser extend on the experience of the evaluating person. On average over all test specimens, the wood failure percentage determined with the semi-automatic method was slightly lower compared to the results of visual rating $\left(\triangle \mathrm{WFP}_{\text {old-new }}+8 \%\right)$. This is explained mainly by the fact that the new method interprets every failure close to the interface as adhesion failure. The highest differences in results were identified on Norway spruce specimens bonded with UF $\left(\Delta \mathrm{WFP}_{\text {old-new }}+30.2 \% ; \mathrm{SD} \pm 17.3\right)$ or MUF $\left(\Delta \mathrm{WFP}_{\text {old }- \text { new }}+22.2 \%\right.$; $\left.\mathrm{SD} \pm 19.0\right)$ adhesive. In those cases the conventional method resulted in much higher percentages of wood failure, simply because the adhesion

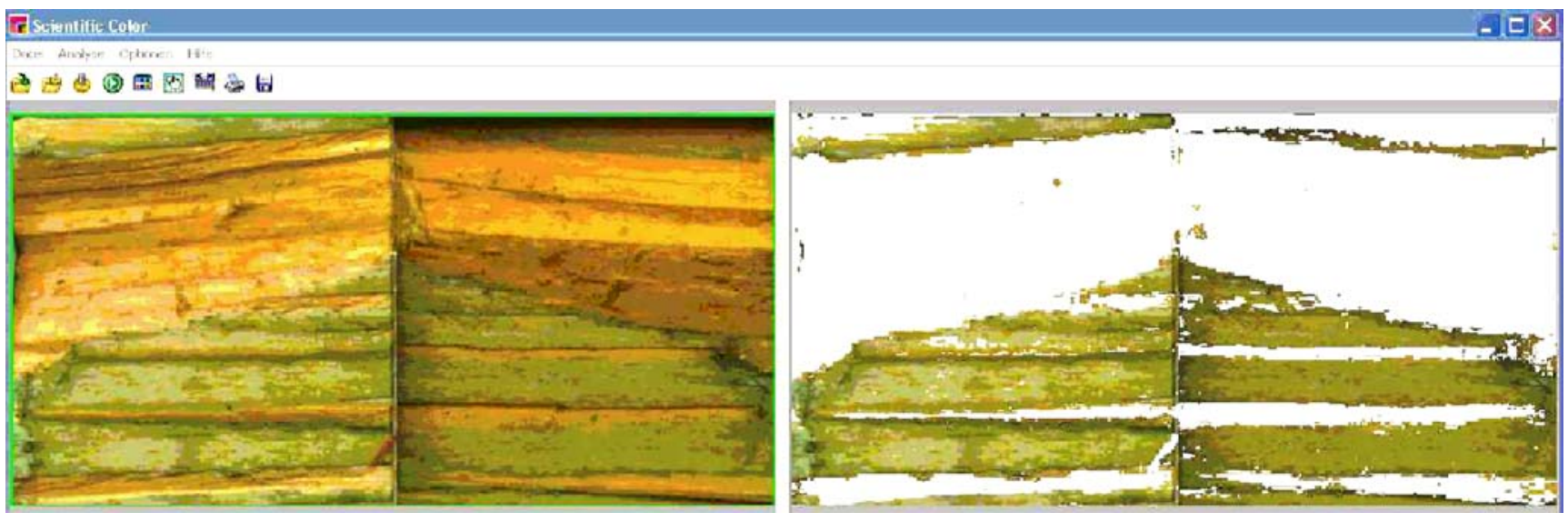

Fig. 1 Program window in DatInf ${ }^{\circledR}$ Scientific Color; left the two stained parts of a shear test specimen; right the analysed surface with white areas indicating wood failure of $55 \%$

Abb. 1 Programmfenster in DatInf ${ }^{\circledR}$ Scientific Color; links die zwei gefärbten Hälften einer Scherprobe; rechts die analysierte Fläche, wobei weiße Bereiche Holzfaserbruch in Höhe von $55 \%$ abbilden 
Fig. 2 Procedure to determine the wood failure percentage on shear test specimens

Abb. 2 Auswertungsroutine für die Bestimmung des

Faserbruchanteils an Scherproben

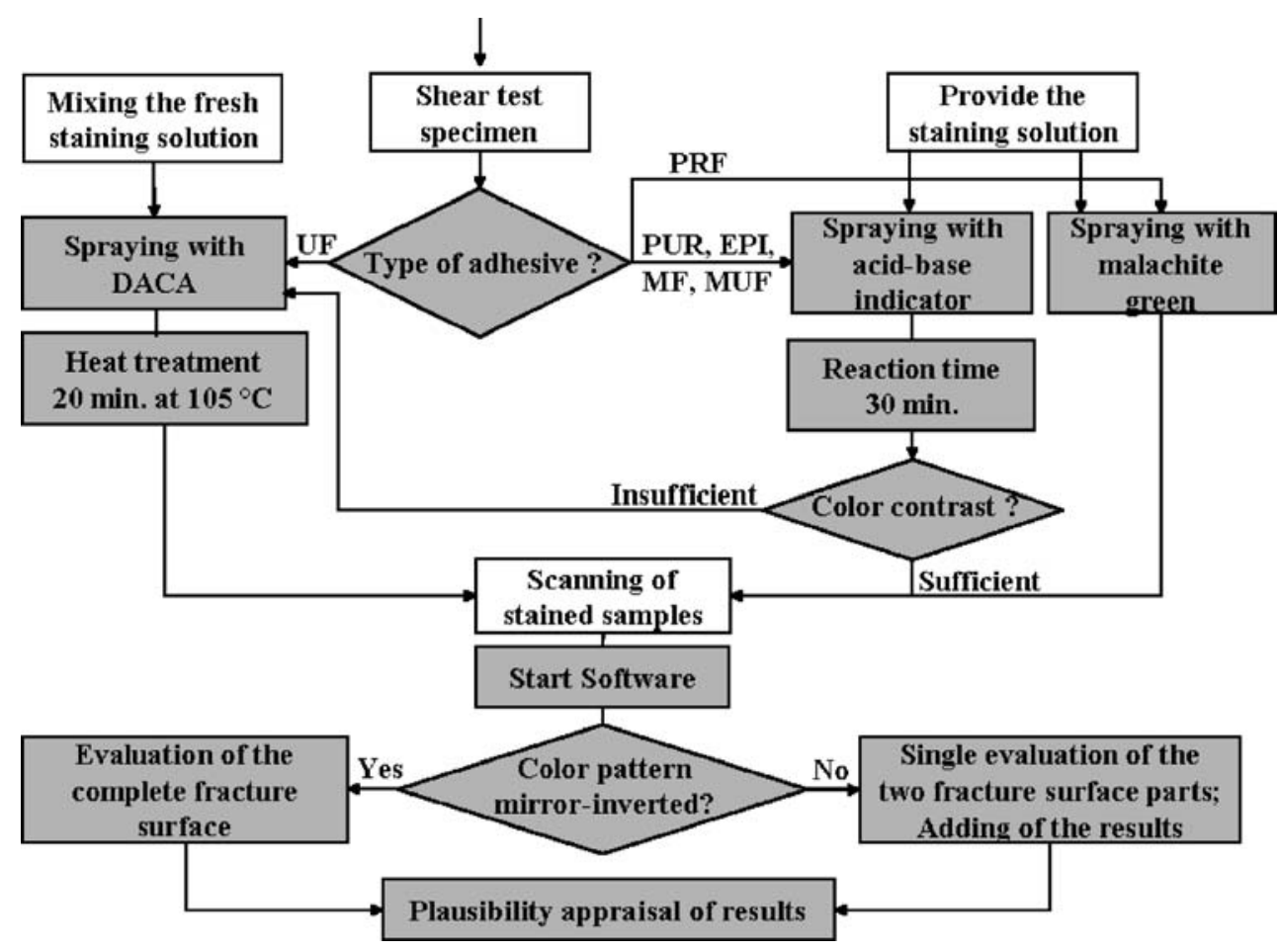

Fig. 3 Differences in wood failure percentage $(\triangle \mathrm{WFP})$ of various wood-adhesive combinations (S spruce, L larch; Boxplot: Box Perc. 25/50/75, Whisker Perc. 5/95, $\times$ Perc. 1/99, - min/max, $\square$ mean) Abb. 3 Differenz des Holzfaserbruchanteils ( $\Delta$ WFP) von verschiedenen

Holz-Klebstoff-Kombinationen (S Fichte, L Lärche; Boxplot: Box Perc. 25/50/75, Whisker Perc. 5/95, $\times$ Perc. 1/99, $\min / \max , \square$ Mittelwert)

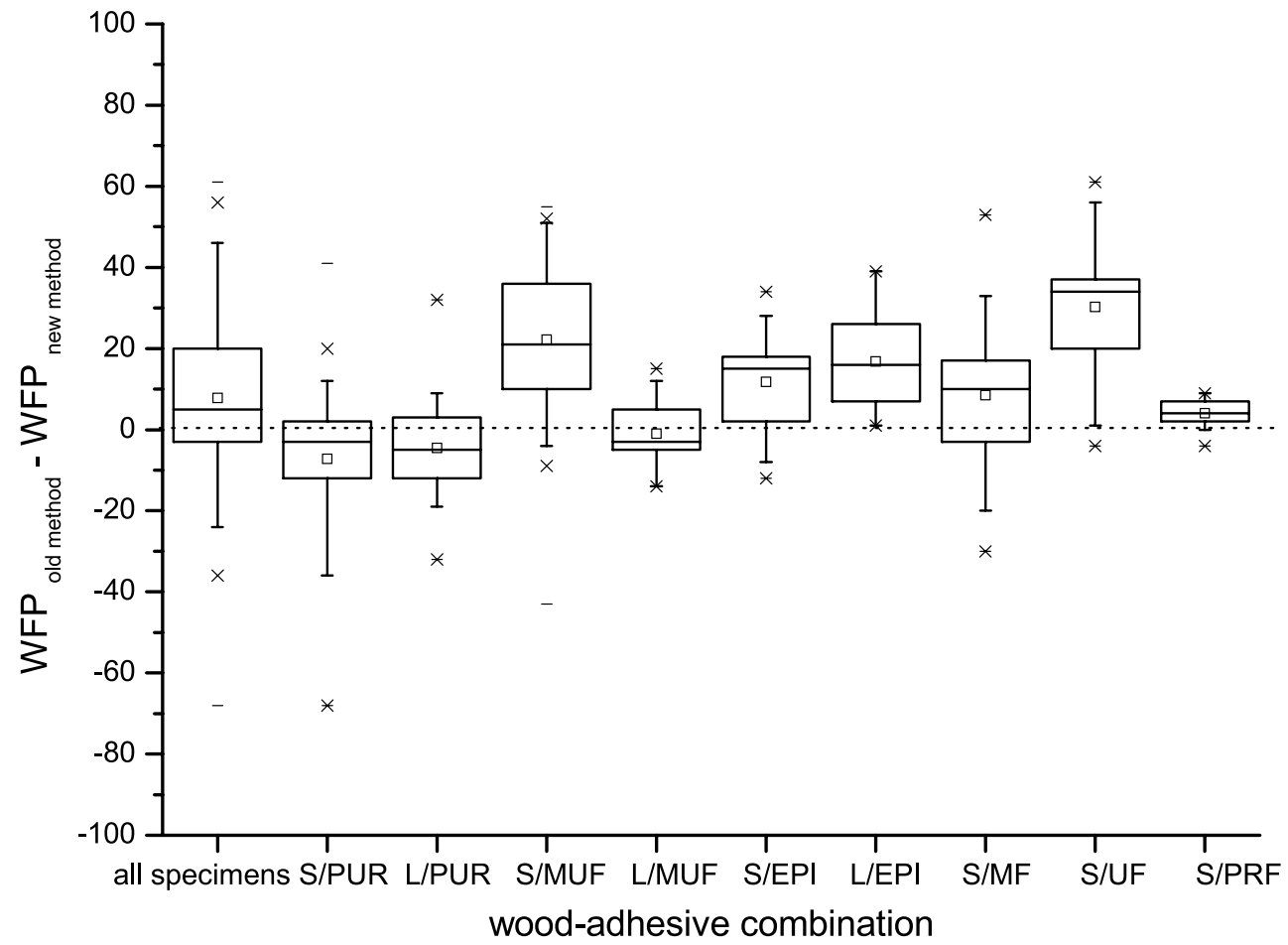

failure was hardly visible without staining. In contrast, larch specimens bonded with MUF showed nearly identical results with both methods just as spruce specimens glued with PRF. On specimens bonded with PUR slightly higher wood failure percentages $\left(\triangle \mathrm{WFP}_{\text {old-new }}-4.5 \% ; \mathrm{SD} \pm 11.8\right.$ for larch wood; $\Delta \mathrm{WFP}_{\text {old-new }}-7.2 \%$; $\mathrm{SD} \pm 21.3$ for spruce) were determined with the new method compared to the results of conventional visual rating. These results are visualized in Fig. 3.

In addition to the determined wood failure percentage, in most cases contrast staining allows a definition of the failure mode, because adhesion failure and cohesion failure are producing different types of color patterns (mirror-inverted or an irregular color pattern). 


\section{Conclusion}

The proposed semi-automatic method can be used alternatively for determining wood failure percentage on shear test specimens.

The procedure requires additional effort in regard to manipulation of the specimens and instrumentation including software, but delivers more objective results than the visual method. Additionally, the new method enables a definition of the failure mode based on the pattern of the colored fracture surfaces. This could be advantageous for identifying sources of existing bonding problems. Finally an electronic documentation of analyzed surfaces and results obtained is possible, which is of great convenience for quality control.

In conclusion, the semi-automatic method described here can be recommended for both the quality control in the glulam industry and for research purposes.

More detailed information about the new method is given in Künniger (2007).

Acknowledgement Financial support of 'Fonds zur Förderung der Wald- und Holzforschung', FFWH Nr. 2006.05 is gratefully acknowledged.

\section{References}

EN 301 (2001) Adhesives, phenolic and aminoplastics, for loadbearing timber structures - Classification and performance requirements

EN 386 (2001) Glued laminated timber - Performance requirements and minimum production requirements

EN 392 (1995) Glued laminated timber - Shear test of glue lines

Dibuz JJ, Shelton FJ (1967) Glueline Identification. For Prod J 17(10):20-22

DatInf ${ }^{\circledR}$ Scientific Color (2007) www.datinf.de

Gibson MD, Krahmer RL (1980) Staining to Make Urea-Formaldehyde Resin Visible on Glued Wood Surfaces. For Prod J 30(1):46-48

Ginzel W, Stegmann G (1970) Nachträgliche Anfärbung von Harnstoff-Formaldehydharz-Bindemitteln auf beleimten Holzspänen zur visuellen Beurteilung der Leimverteilung. Holz Roh- Werkst 28(8):289-292

Künniger T (2007) Automatische Bestimmung des prozentualen Faserbruchanteils bei der industriellen Klebfestigkeitsprüfung. FFWH Abschlussbericht. Empa Wood Laboratory, Duebendorf

Paulitsch M (1986) Methoden der Spanplattenuntersuchung. SpringerVerlag, Berlin Heidelberg New York Tokyo

Plath L (1970) Mikroskopische Untersuchung von Holzverleimungen. Adhäsion 14(9):318-323, 336

Schriever E (1981) Einfacher qualitativer Nachweis von Harnstofformaldehydharzen und Diisocyanaten in Holzwerkstoffen. Holz Roh- Werkst 39:227-229

Zeppenfeld G, Grunwald D (2005) Klebstoffe in der Holz- und Möbelindustrie. DRW-Verlag Weinbrenner \& Söhne GmbH \& CoKG, Leinfelden-Echterdingen 